\title{
Concessionárias do setor elétrico brasileiro e sua política de dividendos: influência de variações do PIB
}

\author{
Nome Alexandre da Silva \\ Instituição/Afiliação - \\ País \\ Resumo da \\ Biografia \\ Contato principal para correspondência.
}

\section{Resumo:}

Uma característica das empresas do setor elétrico é o de pagar altos dividendos. Nossa hipótese é de que em períodos com maior crescimento do PIB, os investimentos das empresas do setor elétrico também aumentem. Este aumento de investimento, por sua vez, vai resultar em diminuição da distribuição de dividendos, e isto ocorrerá principalmente em empresas de menor porte dadas maiores restrições de crédito a elas. Por meio do teste chi-quadrado, encontramos uma relação inversa entre a variação de PIB superior a $3 \%$ com o investimento no período. Além disso, em períodos de variação do PIB e o investimento no período. Além disso, em períodos de alto crescimento (variação do PIB superior a 3\%), o financiamento externo tende a ser negativo, enquanto que o payout de dividendos tende a aumentar nesses períodos. Nossos resultados, portanto, apontam para um modelo de gestão dependente de crédito para sua expansão. Empresas do setor elétrico podem estar, portanto, apesar da grande formação de caixa, valendo-se de crédito externo para seu investimento. Em outras palavras, esperávamos que a expansão do PIB estivesse na proporção inversa da distribuição de dividendos, e não na proporção direta, como observamos. O fato de que as empresas do setor elétrico conseguem obter recursos facilmente no mercado, não havendo necessidade de reter lucros, pode explicar nossos resultados.

Palavras-chave: Dividendos. Investimentos. Setor elétrico.

\section{Introdução}

As empresas do setor elétrico brasileiro, diferentemente de outros setores, possuem características próprias que lhes colocam num grupo a parte, distinto mesmo da teoria econômica convencional. Por serem empresas de utilidades públicas (em inglês "utilites"), operam a partir de concessões públicas (daí também o termo "concessionárias"). Independente de sua forma de atuação, que varia desde a geração de energia elétrica, passando pela transmissão e distribuição, seu serviço prestado está submetido a agências regulatórias que, além de fiscalizarem a qualidade da prestação do serviço, definem a precificação das tarifas cobradas.

Estamos diante, portanto, de uma mercadoria que não sofre um quadro de "concorrência perfeita" . Somado a isto, um preço que é chamado de "tarifa", ou seja, ligado a não somente

\footnotetext{
${ }^{1}$ Existem apresentam quatro modos pelos quais se justifica o surgimento de um monopólio: a primeira, uma firma pode controlar a oferta total de determinado insumo básico, para um produto. A segunda, uma firma pode tornar-se um monopolista, pois seu custo médio de produção atinge o
} 
índices de preços ou de planilhas de custos, mas a "trade offs" entre demanda e oferta. Um exemplo disso, é o fato de que em momentos de fortes variações na oferta ou demanda, seja em épocas de pouca produção de energia elétrica ou em momentos de pico de consumo de energia como nas tardes de verão, ocorre o uso de geração adicional de energia de termelétricas, que é mais dispendiosa ${ }^{2}$.

Um excesso de demanda, pelo menos no curto prazo, tem que ser corrigido com o aumento de preço. Isso ocorre por que no curto prazo não é possível ajustar a produção. No longo prazo, os elementos associados com os ganhos de escala deveriam ganhar força, devendo haver um aumento da capacidade de produção para atender a uma maior demanda. Mais uma vez, diferente da teoria econômica convencional, o maior consumo não levaria a uma "economia em escala" a longo prazo, com diminuição dos custos e queda de preços, mas aqui, justamente o contrário: aumento de custos e de tarifas (Justiniano, Primiceri e Tambalotti, 2008). Segundo a Empresa de Pesquisa Energética (2015), para compensar o aumento na demanda energética, a curto prazo, fontes mais caras de energia elétrica como a termoelétrica são ativadas, levando ao aumento de custo.

Uma crescente demanda por energia elétrica acompanha períodos de crescimento econômico, necessitando investimentos constantes. Dado o período prolongado de amadurecimento desse tipo de investimento, ele também torna-se necessário em períodos de menor pujança econômica. Uma fonte barata de investimentos são os lucros. Assim, o pagamento de altas somas em dividendos para os acionistas poderia comprometer o volume necessário de investimentos.

\section{Consumo de energia elétrica e produto interno bruto}

O consumo de energia elétrica no Brasil teve um crescimento médio de 6,72\% nos últimos 35 anos (Empresa de Pesquisa Energética, 2015). No período pós-crise ${ }^{3}$, de 2002 a 2005, o crescimento médio foi de 4,91\% ao ano. Historicamente, o consumo de energia elétrica, em taxas superiores às de crescimento do PIB vem se repetindo há cerca de 35 anos e deve se manter assim no futuro próximo.

Institucionalmente, o setor sofreu profundas transformações desde os anos 90. Em 1996, através do Projeto RE-SEB (Projeto de Reestruturação do Setor Elétrico Brasileiro), iniciou-se a fase de concepção do novo modelo, sob a coordenação da Secretaria Nacional de Energia do Ministério de Minas e Energia, chegando-se à conclusão de que era preciso criar uma Agência Reguladora (ANEEL - Agência Nacional de Energia Elétrica), um operador para o sistema (ONS - Operador Nacional do Sistema Elétrico) e um ambiente (MAE - Mercado Atacadista de

mínimo ponto em que a quantidade produzida é suficientemente elevada para satisfazer todo o mercado a um preço lucrativo. A terceira, diz respeito a uma firma que pode obter o monopólio de produção de um bem através de patentes sobre o produto desse bem. A quarta, uma empresa pode tornar-se monopolista porque um órgão do governo lhe franqueou uma parte do mercado (Pindyck; Rubinfeld, 2013).

${ }^{2}$ A elasticidade preço da demanda mede o quanto a quantidade demandada muda devido a uma alteração nos preços. Se a curva de demanda é elástica, receita total cai quando o preço aumenta. Se a curva de demanda é inelástica, receita total aumenta quando o preço aumenta.

${ }^{3}$ Referimo-nos à crise do ano de 2001, onde, devido ao consumo de energia elétrica no Brasil estar superando a capacidade de geração naquele ano, o então presidente Fernando Henrique Cardoso, criou através de medida provisória a Câmara de Gestão da Crise de Energia (GCE), com a finalidade de administrar a crise de fornecimento de energia elétrica que ameaçava o país. A GCE foi responsável pela implantação do racionamento de energia elétrica de junho de 2001 a fevereiro de 2002. O racionamento de energia elétrica mobilizou grande parte do país, trazendo para o setor elétrico brasileiro o foco das atenções, que passou a ter um destaque que até então não possuía (BARDELIN, 2003). 
Energia Elétrica), através de uma operadora (ASMAE - Administradora de Serviços do Mercado Atacadista de Energia Elétrica), onde fossem transacionadas as compras e vendas de energia elétrica. O Projeto RESEB foi concluído em agosto de 1998, com toda a concepção do novo arcabouço setorial definida. Assim, de um modelo antigo, baseado em financiamento através de recursos públicos, empresas estatais verticalizadas, maioria de empresas estatais, monopólios com competição inexistente e tarifas reguladas para um modelo novo de: financiamento através de recursos públicos (BNDES) e privados, concessionárias divididas por atividade: geração, transmissão, distribuição e comercialização, abertura para empresas privadas, competição na geração e comercialização e preços livremente negociados na geração e comercialização.

Os aspectos de uso de energia, portanto, estão intimamente relacionados ao comportamento da economia e um dos principais indicadores que medem o comportamento da economia nos países é o PIB (produto interno bruto) que representa, em definição bem simplificada, o valor dos bens e serviços produzidos em um determinado período. A variação acumulada do consumo de energia elétrica no Brasil sempre tem sido superior a variação do PIB (Empresa de Pesquisa Energética, 2015). A ocorrência deste fato mostra a necessidade de uma quantidade maior de investimentos no setor elétrico nas áreas de geração, transmissão e distribuição, bem como de maior eficiência energética, sob pena de aumentos de custos operacionais que se refletirão nas tarifas.

Em geral, quanto maior o PIB per Capita de um país, maior é o poder de compra de cada habitante médio e maior é a demanda individual de energia elétrica, supondo uma elasticidade renda da demanda positiva. Segundo dados do Ministério de Minas e Energia, o consumo per capita de energia elétrica no Brasil aumentará cerca de $45 \%$ em relação ao atual, alcançando $3.561 \mathrm{kWh} /$ ano em 2020. Para sustentar o crescimento econômico projetado, estima-se que o Brasil necessitará de investimentos superiores a $\mathrm{R} \$ 380$ bilhões no setor geração de energia elétrica até 2022.

\section{Dividendos}

A decisão de distribuir lucro deve compatibilizar pelo menos três fatores: os interesses da comunidade dos acionistas, o financiamento das novas oportunidades de investimentos e o conteúdo informacional da política de dividendos (Pagano, 2007). Algumas empresas, por sua vez, procuram adotar determinadas práticas, nas quais se inclui uma política de dividendos mais generosa e estável. Nessa linha, a maior distribuição de dividendos seria considerada positiva para atenuar os conflitos existentes, garantindo aos acionistas minoritários maior fluxo de caixa e reduzindo a possibilidade de desperdício por parte dos acionistas majoritários e administradores (Hilferding 1985). A política de dividendos, portanto, não é apenas uma decisão sobre o quanto pagar ao acionista. Ela também é uma decisão sobre o quanto ficará retido na entidade, bem como dos motivos que levaram a esta retenção (Loss \& Sarlo-Neto 2003).

A política de dividendos do Brasil distingue-se daquela estabelecida em países desenvolvidos como Estados Unidos e Inglaterra. Configurações de obrigatoriedade no pagamento de dividendos, aspectos de contabilização de operações e tributação sobre este tipo de rendimento são exemplos de diferenças comparativas. (Brugni et al. 2011). Os reguladores brasileiros, visando melhorar proteção legal aos acionistas minoritários, estabeleceram um dividendo mínimo obrigatório por meio da Lei 6.404/76.

Apesar disso, de acordo com Mota (2007), as conclusões de estudos internacionais não podem ser aplicadas diretamente ao mercado brasileiro, já que há uma série de particularidades, dentre as quais se destacam: (a) existência de dividendo mínimo obrigatório; (b) possibilidade de pagamento de juros sobre capital próprio; (c) grande concentração da propriedade; e (d) dividendos, numa visão fiscal, são mais vantajosos que as recompras de ações. Ainda segundo 
o autor, a existência de fluxo de caixa, a estabilidade desses fluxos, o não comprometimento com o endividamento, a preocupação com a governança corporativa e a existência de poucas oportunidades de investimento são fatores que levam as empresas a distribuírem uma maior parte dos seus lucros na forma de dividendos e/ou juros sobre capital próprio.

\section{Setor elétrico e dividendos}

Uma característica das empresas do setor elétrico é o de pagar altos dividendos (Brighman, Gapenski \& Ehrhardt 2001), em alguns casos com payout superior a 100\%, fato este também presente nas empresas do setor elétrico do Brasil (Rodrigues et al, 2016). A alta lucratividade, associada à baixa volatilidade dos lucros, segundo Myers (1984), também acaba servindo como motivação para pagamento de altos dividendos. Parece paradoxal, dada a necessidade de altos investimentos tanto em geração quanto em transmissão e distribuição e o crescente aumento no consumo. Uma possível hipótese remete aos trabalhos de Modigliani e Miller (1958), em que mostram que é indiferente para a empresa crescer a partir do uso de financiamento externo ou interno. Assim, para uma empresa elétrica, com fluxo de caixa garantido a partir de uma concessão pública que pode durar décadas, a chance de inadimplência seria reduzida, garantindo, portanto, empréstimos de longo prazo e com juros baixos, deixando o lucro líquido como instrumento para o pagamento de dividendos para acionistas.

Segundo Smith (1986), as utilities pagam mais dividendos que empresas não reguladas. O trabalho de Paul Simshauser e Angela Catt (2012), sobre concessionárias do setor elétrico, relacionam o contexto de megaciclo de investimentos (década de investimento sucedida por década de baixo investimento e de alto pagamento de dividendos) com o pagamento de dividendos. Os autores sugerem que, para ocorrer um adequado investimento, deve haver diminuição do payout, sem haver alteração no retorno por ação (e as teorias de Lintner, sobre Relevância de Dividendos). Este fato também foi demonstrado no trabalho de Santana (2006), que demonstrou não haver correlação entre dividend yield e retorno por ação.

A despeito da vasta literatura sobre políticas de dividendos, a maioria dos estudos excluem as empresas reguladas de suas análises. A explicação para excluir as firmas reguladas é que os reguladores, direta ou indiretamente, ditam a quantidade de dividendos que as empresas podem pagar. Estudos sobre empresas reguladas mostram que, na média, uma firma regulada e menos arriscada; tem menor taxa de crescimento; tem muito menos insider holding e tem menos oportunidades de investimentos, mas paga uma maior quantidade de dividendos. Segundo Souza, Jacob e Willis (2015), num ambiente de negócios regulados, muitos dos tradicionais argumentos usados para explicar políticas de dividendos não se aplicam.

Empresas do setor elétrico, por estarem incluídas no grupo de empresas reguladas, geralmente distribuem dividendos muito generosos para seus acionistas. A despeito disso, a política de dividendos de empresas reguladas atrai pouca atenção pela literatura existente, uma vez que estas companhias são geralmente consideradas como menos arriscadas, insuladas da disciplina de produção e mercado de capitais e onde os reguladores diretamente ou indiretamente afetam os ganhos das empresas e em consequência seus payouts.

\section{Investimento e restrições de crédito}

Decisões de investimento estão sensivelmente ligadas a restrições de crédito (Kirch, Procianoy \& Terra, 2014). Empresas com maior restrição fazem maior uso de disponibilidade interna de recursos, como o fluxo de caixa (Fazzari e Athey, 1987). Esteves Filho e Ness Jr. (2005) indicam que as firmas menores, com menor dividend payout, menor liquidez, maior endividamento e de capital nacional (principalmente as estatais) apresentam maior sensibilidade do investimento aos fluxos de caixa do que suas respectivas contrapartes. 
Diante dos argumentos acima expostos, de que empresas do setor elétrico distribuem dividendos altos, de que a necessidade de investimentos neste setor é crescente, e de que, visto que o consumo de energia geralmente é superior a variação do PIB, seria de se esperar que os investimentos sejam maiores neste período de crescimento acentuado do PIB. Nossa hipótese é de que em períodos com maior crescimento do PIB, os investimentos das empresas do setor elétrico também aumentem, e que este aumento de investimento vai resultar em diminuição de distribuição de dividendos, e que isto ocorrera principalmente em empresas de menor porte dadas maiores restrições de credito a elas. Já as empresas grandes, com menores restrições de crédito, devem experimentar menor variação nos dividendos, pois podem financiar os novos investimentos com recursos externos (financiamento e emissão de ações, por exemplo).

Para atender o objetivo proposto, o restante do estudo está estruturado da seguinte forma: na seção 2 apresentam-se os aspectos metodológicos, inclusive os procedimentos de coleta e tratamento dos dados; na seção 3 analisam-se os resultados dos testes empíricos; e na seção 4 apresentam-se algumas considerações finais acerca do estudo.

\section{Metodologia}

Nossa hipótese de estudo é que as empresas do setor elétrico diminuem seu pagamento de dividendos em períodos de alto crescimento do PIB, ao desviar estes recursos para realizar investimentos em aumento de capacidade tanto de geração quanto de transmissão e distribuição. Além disso, também testaremos a relação entre o pagamento de dividendos com o financiamento externo das empresas, bem como entre o financiamento externo e investimentos das empresas do setor elétrico. Nossa hipótese é de que em períodos de grande crescimento do PIB as empresas utilizarão maior financiamento externo para seus investimentos.

Os dados foram coletados a partir do banco de dados do site Economatica®, onde buscamos as empresas de capital aberto do setor elétrico brasileiro. Compilamos seus balanços patrimoniais não-consolidados de 1994 a $2007^{4}$ corrigidos para valores de 2014. Usamos o teste chiquadrado de Pearson com nível de significância estatística em $\mathrm{p}<0,1$.

Dividimos as empresas em 2 grupos: as empresas "grandes" com ativos superiores a 6 bilhões de reais e as "pequenas", com ativos inferiores a esse valor. Esta divisão surgiu a partir de diferentes valores de ativos totais entre ambas classificações. Somente neste cut-off é que foram encontradas diferenças significativas entre ambos grupos quanto a distribuição de dividendos. Foram selecionadas 60 empresas, em que 20 foram classificadas como grandes e 40 classificadas como pequenas ${ }^{5}$. O total de observações ficou em 543 , devido ao fato de que muitas empresas surgiram ou desapareceram em meio ao período analisado.

Se nossa hipótese for verdadeira, as empresas diminuiriam seus dividendos em períodos de alto crescimento do PIB. Para tanto, separamos nossa amostra em períodos de baixo crescimento (< $3 \%$ ) e alto crescimento do PIB $>3 \%)^{6}$ e em períodos de crescimento nos dividendos e decréscimo nos dividendos. Feita essa segmentação, testamos a associação entre crescimento do PIB e crescimento dos dividendos (teste qui-quadrado de Pearson).

Comparamos a variação do PIB com a variação da distribuição de dividendos ${ }^{7}$. Delimitamos a variação de distribuição de dividendos ( $\Delta$ Div) através da variação anual da distribuição de dividendos $(\Delta \mathrm{DD})$ em relação ao modulo da variação do lucro líquido $(\Delta \mathrm{LL})(1)$.

$$
\Delta \mathrm{Div}=\Delta \mathrm{DD}>\Delta \mathrm{LL}
$$

\footnotetext{
${ }^{4}$ a data limite para 2007 corresponde a mudança da DOAR para a DFC (dividendos declarados x dividendos pagos).

${ }^{5}$ De acordo com a média dos ativos totais nos balanços corrigidos para valores de 2014 .

${ }^{6}$ A média de variação do PIB no período estudado foi de $3,2 \%$ e sua mediana de $3,3 \%$.

7 inclui-se os juros sobre capital próprio
} 
Comparamos também com investimento e financiamento externo. Definimos investimento (Invest) como a variação do ativo não-circulante $(\triangle \mathrm{AtNC})$ somada à depreciação ${ }^{8}$ (deprec) (2). As empresas foram separadas por investimento maior e menor a zero e financiamento externo maior e menor a zero.

$$
\Delta \text { Invest }=\Delta \mathrm{AtNC}+\text { deprec }
$$

Financiamento externo (FinExt) foi definido como variação de passivo não-circulante (PaNC) somado a variação do patrimônio líquido (PL), diminuído pelo seu lucro líquido (LL) e somado aos seus dividendos (Div) (3).

$$
\text { FinExt }=\Delta \mathrm{PaNC}+\Delta \mathrm{PL}-\mathrm{LL}+\mathrm{Div}
$$

Analisamos também as relações entre todas essas variáveis (variação do PIB, variação de dividendos, investimento e financiamento externo). Por fim, comparamos a relação entre lucro líquido e tamanho de empresa e com variação do PIB.

\section{Apresentação e análise dos dados}

A tabela apresenta o teste 1, que compara a variação anual do PIB com a variação de ativo nãocirculante + depreciação (ou seja, investimento). Houve uma correlação inversamente proporcional estatisticamente significativa entre variação de PIB superior a $3 \%$ com o investimento no período. Ao segmentar-se as empresas por tamanho de ativos, mostrou-se que a correlação se manteve nas empresas consideradas grandes (ativos maiores de R $\$ 6$ bilhões) e pequenas (ativos menores de $\mathrm{R} \$ 6$ bilhões). Portanto, em períodos de variação do PIB superior a $3 \%$, a taxa de investimento tende a diminuir. Nossa hipótese sugere que faz-se necessário maior investimento, pois o aumento do consumo supera a variação do PIB. Os resultados, portanto, contrariam nossa hipótese. Uma possível explicação para esses resultados seria que se as empresas olham para a demanda (PIB) futura para determinar seus investimentos correntes, haveria maior investimento em períodos de menor PIB (antevendo que no futuro, com maior demanda (PIB) maior será a necessidade de energia).

O teste 2 compara a variação anual do PIB com a variação de dividendos sobre a variação do módulo do lucro líquido (variação de distribuição de dividendos). Houve uma correlação positiva estatisticamente significativa entre variação de PIB superior a $3 \% \mathrm{com}$ maior distribuição de dividendos. Ao segmentar-se as empresas por tamanho de ativos, mostrou-se que a correlação se manteve nas empresas com ativos de valor superior a $R \$ 6$ bilhões. No entanto, nas empresas com ativos inferiores a R\$ 6 bilhões, não houve correlação estatisticamente significante entre variação do PIB e distribuição de dividendos. Assim, conclui-se que em períodos de grande crescimento do PIB, distribui-se mais dividendos. Contudo, isto não ocorre em empresas de menor tamanho. Nesses períodos, parece que o excesso de recursos não é distribuído na forma de dividendos e sim mantido como reserva para financiar futuros projetos de investimento.

O teste 3 compara a variação anual do PIB com o financiamento externo. Houve uma correlação inversamente proporcional estatisticamente significativa entre variação de PIB superior a 3\% com financiamento externo no período. Ao segmentar-se as empresas por tamanho de ativos, mostrou-se que a correlação se manteve nas empresas com ativos de valor superior a $\mathrm{R} \$ 6$ bilhões. No entanto, nas empresas com ativos inferiores a $\mathrm{R} \$ 6$ bilhões, não houve correlação significativa entre variação do PIB e financiamento externo. Assim, a exceção das empresas

\footnotetext{
8 inclui amortização
} 
pequenas, em períodos de variação do PIB superior a 3\%, há menor uso de financiamento externo. Isso talvez se deva ao fato de que os investimentos também têm relação negativa com o PIB.

O teste 4 compara variação anual do PIB com a variação de lucro líquido, não havendo correlação estatisticamente significativa entre ambos. Contudo, em empresas grandes, em períodos de variação do PIB superior a 3\%, o lucro líquido cresceu menos; o mesmo não ocorreu nas empresas pequenas. Parece um paradoxo: esperaríamos que o lucro líquido aumentasse em períodos de maior consumo. Seria, então, esta queda no lucro líquido o verdadeiro freio para o investimento nestes períodos de PIB alto? (pelo menos este argumento explicaria este comportamento para as empresas grandes).

O teste 5 compara a variação de distribuição de dividendos com a variação de investimento. Não houve correlação entre estas variáveis, nem mesmo ao se estratificar pelo tamanho da empresa. Se o investimento é alto em determinado período os dividendos não necessariamente serão baixos (ou altos) como poderia se esperar se houvesse uma relação de substituição (complementariedade) entre eles.

O teste 6 compara a variação anual do investimento com o financiamento externo. Houve uma correlação diretamente proporcional estatisticamente significativa entre variação anual do investimento com a variação de financiamento externo no período. Ao segmentar-se as empresas por tamanho de ativos, mostrou-se que a correlação se manteve nas empresas consideradas grandes (ativos maiores de R $\$ 6$ bilhões) e pequenas (ativos menores de $\mathrm{R} \$ 6$ bilhões). Portanto, investimento e financiamento externo estão intimamente relacionados.

O teste 7 compara a variação de distribuição de dividendos com a variação de financiamento externo. Não houve correlação entre estas variáveis, nem mesmo ao se estratificar pelo tamanho da empresa. Assim, empresas com alta distribuição de dividendos não necessariamente contraem financiamento externo para complementar os recursos necessários para cobrir todos os usos de caixa.

Nossos resultados contrariam os trabalhos de Procianoy (2003) e Megliorini (1998), que demonstraram que em períodos de alta atividade econômica, as empresas fazem uso de todos os fundos disponíveis, restringindo a distribuição de dividendos. Procianoy (1994) demonstrou que as empresas tendem a reter a maior quantidade possível de dividendos devido as incertezas quanto a escassez de recursos disponíveis a longo prazo. Contudo, eles fazem a ressalva de que, dependendo do setor estudado, esta evidência pode não ser válida.

Diante do acesso que as empresas do setor elétrico possuem a crédito diante de sua alta formação de caixa, a incerteza relatada por Procianoy (2003) desaparece, liberando os dividendos para serem distribuídos. Nossos resultados, além disso, estão em consonância com o trabalho de Loss (2006), que demonstrou em análise empírica de empresas listadas na Bovespa que não há relação entre política de dividendos e política de investimentos.

Nossos dados mostram que distribuição de dividendos está descolada dos investimentos. As empresas, principalmente as maiores, por terem maior acesso a crédito, muitas vezes subvencionados, podem se permitir a este maior pagamento de dividendos. Este maior pagamento de dividendos, por sua vez, poderia ser utilizado como um sinal de bom funcionamento da empresa (Efeito Sinalizador), além de uma forma de atrair investidores desejosos de receberem maior quantidade de dividendos do que aumento de ganhos de capital, mesclando, assim, o "Efeito Clientela" da Teoria de Irrelevância dos Investimentos (Modigliani \& Miller 1961) com o efeito "Pássaro na Mão" da Teoria de Relevância dos Dividendos (Lintner 1956 e Gordon 1959). Nossos resultados não são consistentes com a hipótese levantada por Procianoy (2003), que afirma que empresas com grandes oportunidades de investimento tendem a reter mais lucros. Se entendermos que grandes variações no PIB sinalizam grandes oportunidades de investimentos, nossos resultados vão em direção contrária. 
Conforme nossos dados, o financiamento externo está ligado ao investimento; se a empresa investe menos em períodos de alta variação positiva do PIB, e que a distribuição de dividendos não guarda relação com financiamento externo, fica evidente a menor necessidade de financiamento externo. Os resultados sugerem que a política de investimento e dividendos dessas companhias não estão relacionadas. Estes investimentos, contudo, são geralmente feitos a partir de financiamento externo, de acordo com o trabalho de Gomes et al. (2002). Num cenário de restrição de crédito, por exemplo, poderia se argumentar que a distribuição de dividendos deveria ser sacrificada em prol de maiores investimentos lucrativos. Não é o que parece estar ocorrendo. As empresas estudadas não apresentam um comportamento como esse (cortando dividendos em períodos de maior investimento). Talvez não sofram de restrições de credito ou o volume de recursos internos é suficiente para atender ambas as demandas de forma satisfatória: dividendos e investimentos. Contudo, as empresas pequenas não aumentaram a distribuição de dividendos quando o PIB aumentou, criando, possivelmente, uma reserva para financiar futuros investimentos sem ter que cortar os dividendos nesses períodos. 


\begin{tabular}{|c|c|c|c|}
\hline \multicolumn{4}{|c|}{ Tabela - Correlação entre as variáveis em estudo $^{1}$} \\
\hline $\begin{array}{l}\text { Tamanho das empresas } \\
\text { selecionadas }\end{array}$ & & & Correlação \\
\hline Teste 1 & $\Delta \mathrm{PIB}>3 \%$ & $\Delta \mathrm{AtNC}+$ deprec $>0$ & \\
\hline Todas & & & Inversa* \\
\hline Grandes $^{2}$ & & & Inversa* \\
\hline Pequenas $^{3}$ & & & Inversa* \\
\hline Teste 2 & $\Delta \mathrm{PIB}>3 \%$ & $\Delta \operatorname{Div}>\Delta \mathrm{LL}$ & \\
\hline Todas & & & Direta* \\
\hline Grandes & & & Direta* \\
\hline Pequenas & & & ausente \\
\hline Teste 3 & $\Delta \mathrm{PIB}>3 \%$ & Finext $>0$ & \\
\hline Todas & & & Inversa* \\
\hline Grandes & & & Inversa* \\
\hline Pequenas & & & ausente \\
\hline Teste 4 & $\Delta \mathrm{PIB}>3 \%$ & $\Delta \mathrm{LL}>0$ & \\
\hline Todas & & & ausente \\
\hline Grandes & & & Inversa* \\
\hline Pequenas & & & ausente \\
\hline Teste 5 & $\Delta \mathrm{AtNC}+$ deprec $>0$ & $\Delta \operatorname{Div}>\Delta \mathrm{LL}$ & \\
\hline Todas & & & ausente \\
\hline Grandes & & & ausente \\
\hline Pequenas & & & ausente \\
\hline Teste 6 & $\Delta \mathrm{AtNC}+$ deprec $>0$ & Finext $>0$ & \\
\hline Todas & & & Direta $* *$ \\
\hline Grandes & & & Direta $* *$ \\
\hline Pequenas & & & Direta $* *$ \\
\hline Teste 7 & Finext $>0$ & $\Delta \mathrm{Div}>\Delta \mathrm{LL}$ & \\
\hline Todas & & & ausente \\
\hline Grandes & & & ausente \\
\hline Pequenas & & & ausente \\
\hline
\end{tabular}

${ }^{1}$ Teste chi-quadrado. ${ }^{2}$ ativos superiores a R $\$ 6$ bilhões. ${ }^{3}$ ativos inferiores a R $\$ 6$ bilhões. $\Delta$ PIB $>3 \%$ : variação alta do PIB; $\triangle \mathrm{AtNC}+$ deprec: variação de ativo não circulante + depreciação; $\Delta$ Div $>\Delta \mathrm{LL}$ : variação de dividendos > variação de lucro liquido; Finext: financiamento externo; $\Delta \mathrm{LL}>0$ : variação positiva do lucro líquido; ${ }^{*} p<0,1 ; p<0,01$. 


\title{
4. Considerações finais
}

Nossos resultados apontam para um modelo de gestão dependente de crédito para sua expansão. Há uma relação entre investimento e financiamento externo, mas não há relação dessas decisões com a política de dividendos, contrariando nossa hipótese de pesquisa. Uma possível explicação: com crédito externo na quantidade desejada, os investimentos podem ser realizados sem maiores restrições a distribuição de lucros. Isso ocorre mesmo entre pequenas empresas, normalmente mais sujeitas a restrições de crédito. Esses resultados também sugerem que esse setor, talvez por ser regulado, não enfrenta restrições de crédito. Compreender melhor a alocação de recursos destas empresas será de grande utilidade para a sociedade como um todo, visto estarem em adequado funcionamento são a base da infraestrutura de bem estar das pessoas bem como da infraestrutura para o progresso econômico das empresas. Dessa maneira, sugerimos que a expansão do PIB deve estar na proporção inversa da distribuição de dividendos, e não na proporção direta, como observamos.

À frente da relevância ou não de pagamento de dividendos, está a necessidade de um permanente ciclo de investimentos no setor elétrico. Além disso, o desenvolvimento de qualquer país (senão todos) está ligado à diminuição dos custos operacionais do setor, o que também demanda maior investimento.

\section{Concessionaires of the Brazilian electric sector and its dividend policy: influence of}

\section{changes in GDP}

\begin{abstract}
:
A special feature of Brazilian electrical system firms is the payment of high amount of dividends. Our hypothesis is that in periods of high growth of GNP, the investment of electrical system firms will also increase. This increase of investment, in turn, will result in falling of dividends distribution, mainly in smallest firms because larger credit restrictions to them. By means of the chi-square test, we find an inverse relation between the GDP variation of more than $3 \%$ with the investment in the period. In addition, in periods of variation of GDP and investment in the period. In addition, in periods of high growth (GDP growth of more than 3\%), external financing tends to be negative, while the dividend payout tends to increase in those periods. Our results, therefore, are driven toward a model of credit management dependent to promote expansion. So, electrical system firms can be using external financing to their investment needs, in despite of high profits. In other words, we expected the expansion of GNP was related to a contrary proportion of payout of dividends, and not in a direct proportion, as we observed. Our results can be explained by the facility of these firms get money in the markets, thus excluding the needs of retain profits.
\end{abstract}

Keywords: Dividends. Investments. Electric Utilities.

\section{Referências}

BARDELIN, C. E. A. Impactos do Racionamento de Energia Elétrica de 2001 e 2002 no Brasil. Em: Power GenLatin América, São Paulo - SP, 2003. Disponível em http://www.seeds.usp.br/pir/arquivos/congressos/CLAGTEE2003/Papers/EUE\%20B066.pdf. Acesso em 12 de julho de 2019. 
BRIGHMAN, E. F., GAPENSKI, L. C.; EHRHARDT, M. C. Administração Financeira: teoria e prática. São Paulo: Atlas, 2001.

BRUGNI, T. V. et al. Influência dos dividendos sobre a informatividade dos lucros contábeis divulgados pelas empresas listadas na Bovespa. Anais: V Congresso AnpCONT, 2011, Vitória, ES. Anais Eletrônicos, 2011.

D'SOUZA, J.; JACOB, J. \& WILLIS,VF. Dividend Policy Responses to Deregulation in the Electric Utility Industry. International Journal of Business Administratio, v. 6, n. 2, 2015

ESTEVES FILHO, M.; NESS JR., W. L. Restrições financeiras aos investimentos fixos de empresas brasileiras listadas em bolsa de valores no período de 1995 a 2003. Anais: Anais do V Encontro Brasileiro de Finanças. SBFin-Sociedade Brasileira de Finanças, 2005. Disponível em: http://bibliotecadigital.fgv.br/ocs/index.php/ebf/5EBF/search/titles. Acesso em 08 de novembro de 2014.

FAZZARI, S. M.; ATHEY, M. J. Asymmetric information, financing constraints, and investment. The Review of Economics and Statistics, v. 69, n. 3, p.481-487, 1987.

GOMES, A. C. S., ABARCA, C. D. G., FARIA, E. A. S. T.; FERNANDES, H. H. O. O Setor Elétrico. Disponível em:

http://www.bndes.gov.br/SiteBNDES/export/sites/default/bndes_pt/Galerias/Arquivos/conhecimento/l ivro_setorial/setorial14.pdf. Acesso em 4 de dezembro de 2014.

GORDON, M. J. Dividends, earning, and stock prices. Review of Economics and Statistics, v. 41, n. 2, p.99-105, 1959.

HILFERDING, R. O capital financeiro. São Paulo: Nova Cultural, 1985.

JUSTINIANO, A., PRIMICERI, G. E.; TAMBALOTTI A. Investment Shocks and Business. Cycles. Federal Reserve Bank of New York Staff Reports, v. 322:1-28, 2008.

KIRCH,G.; PROCIANOY, J. L.; TERRA P. R. S. Restrições Financeiras e a Decisão de Investimento das Firmas Brasileiras. Revista Brasileira de Economia, v. 68, n. 1, p.103-123, 2014.

LINTNER, J. Distribution on incomes of corporations among dividends, retained earnings, and taxes. American Economic Review, v. 46, n. 2, p. 97-113, 1956.

LOSS, L.; NETO, A. S. Política de Dividendos, na prática, é importante? Revista de Contabilidade \& Finanças, v. 14, p. 39-53, 2003.

LOSS, L.; NETO, A. S. O inter-relacionamento entre políticas de dividendos e de investimentos: estudo aplicado às companhias brasileiras negociadas na Bovespa. Revista de Contabilidade \& Finanças, v. 40, p. 52-66, 2006.

MEGLIORINI, E. Lucros Distribuídos - Fator de Atratividade para investimentos em Ações. Editora Faculdade de Ciências Econômicas e Administrativas de Osasco, 1998.

MODIGLIANI, F.; MILLER, M. H. The Cost of Capital, Corporation Finance and the Theory of Investment. The American Economic Review, v. 48, n. 3, p. 261-297, 1958.

MODIGLIANI, F.; MILLER, M. Dividend policy, growth and the valuation of shares. Journal of Business, v. 34, n. 4, p. 411-433, 1961. 
MOTA, D. C. Dividendos, juros sobre capital próprio e recompra de ações: um estudo empírico sobre a política de distribuição no Brasil. Dissertação de mestrado. Fundação Getúlio Vargas. São Paulo, 2007.

MYERS, S. C. The Capital Structure Puzzle. Journal of Finance, v. 39, n. 3. p. 574-592, 1984.

PAGANO, L. Política de Dividendos e Conflito de Interesses. eGesta, v. 3, n. 3, p. 205, 2007.

PINDYCK, R. S.; RUBINFELD D. L. Microeconomia. Pearson Universidades, 2013.

Portal Empresa de Pesquisa Energética. Disponível em:

http://www.epe.gov.br/Estudos/Paginas/default.aspx?CategoriaID=347. Acesso em 10 de novembro de 2014.

PROCIANOY, J. L. Conflitos de agência entre controladores e minoritários nas empresas brasileiras negociadas na bolsa de valores de São Paulo: evidências através do comportamento da política de dividendos após as modificações tributárias ocorridas entre 1988-1989. Tese (Doutorado em Ciências Contábeis). Depto. de Contabilidade e Atuária, Faculdade de Economia, Administração e Contabilidade, Universidade de São Paulo, São Paulo, 1994.

PROCIANOY, J. L.; HEINEBERG, R. Aspectos determinantes do pagamento de proventos em dinheiro das empresas com ações negociadas na Bovespa. Anais: XXVII ENANPAD, Rio de Janeiro, RJ, 2003. Disponível em: http://www.anpad.org.br/enanpad/2003/htm/enanpad2003-fin-1222resumo.html. Acesso em 03 de novembro de 2014.

RODRIGUES, L. C.; CORDEIRO-NETO, J. A.; VILAMAIOR, A. G.; CASTRO, A. C. Estudo das Formas de Distribuição de Dividendos das Organizações pertencentes ao Setor Elétrico Brasileiro. Anais. $20^{\circ}$ Congresso Brasileiro de Contabilidade. Fortaleza, CE, 2016.

SANTANA, L. Relação entre Dividend Yield e retorno total ao acionista abordando aspectos determinantes da política de dividendos: um estudo empírico em empresas com ações negociadas na Bovespa. Anais: $3^{\circ}$ Simpósio Fucape de Produção Científica, Niterói, RJ. 2006. Disponível em: http://docslide.com.br/documents/03-trabalho-24.html. Acesso em 03 de novembro de 2014.

SIMSHAUSER, P.; CATT, A. Dividend policy, energy utilities and the investment megacycle. The Electricity Journal, 25(4):63-87, 2012.

SMITH, C. W. Raising Capital: Theory and Evidence. Midland Corporate Finance Journal, Spring, p. 6-22, 1986. 